\title{
A baba e a Nova Mulher nos cartazes soviéticos dos anos 1920-1930
}

\author{
Ekaterina Vólkova Américo' \\ Thaiz Carvalho Senna'
}

I - UFF

Rio de Janeiro (RJ), Brasil

Resumo: A representação da mulher nos cartazes soviéticos nas primeiras décadas após a revolução de 1917 oferece um campo extremamente fértil para a análise das transformações do papel da mulher ocorridas na nova sociedade. Para a nossa análise histórico-semiótica, foram escolhidos dois cartazes: Mulher, aprenda ler e escrever! de Elizavieta Krúglikova (1923) e Abaixo a escravidão da cozinha! de Grigóri Shegal (1931). Ambos evidenciam a oposição entre a baba, isto é, mulher atrasada e analfabeta do passado e a Nova Mulher (definição de Aleksandra Kollontai), bem como algumas contradições presentes no discurso oficial nas primeiras décadas pós-revolução.

Palavras-chave: cartaz soviético; estudos da tradução; representação do feminino; semiótica da cultura; história.

Abstract: The baba and the New Woman on the Soviet posters of the 1920s-1930s - The representation of women in Soviet posters in the first decades after the revolution of 1917 offers an extremely fertile field for the analysis of the transformations of the women's role in the new society. For our historical-semiotic analysis, we chose two posters: Woman, learn to read and write! by Elizaveta Kruglikova (1923) and Down with kitchen slavery! by Grigori Shegal (1931). Both of them made clear the opposition between the baba, that is to say, backward and illiterate woman of the past, and the New Woman (definition of Alexandra Kollontai), as well as some contradictions in the official discourse in the first decades after the revolution.

Keywords: soviet poster; translation studies; women's representation; culture's semiotics; history.

\section{Introdução}

Nosso objetivo é investigar os novos papéis atribuídos às mulheres pelo Estado soviético, por meio de uma análise histórico-semiótica dos cartazes soviéticos das primeiras 
décadas pós-revolução. Promulgando o discurso da emancipação feminina, os cartazes por vezes corroboraram, por vezes transgrediram os lugares historicamente reservados à mulher, nesse processo repleto de limitações e contradições.

Ao todo, no decorrer da nossa pesquisa, foram analisados e traduzidos 17 cartazes, que vão desde o ano de 1918 até o ano de 1953. Em todos eles, faz-se presente a figura feminina, geralmente representada em pares, como a mãe e a filha, a não comunista e a comunista, a analfabeta e a alfabetizada, a baba e a Nova Mulher. Escolhemos, para esse artigo, dois cartazes em que se faz explícito esse último par - isto é, a mulher antiga, antiquada, frente à moderna e revolucionária. Essa escolha deu-se, sobretudo, pela possibilidade de analisar a construção de uma nova imagem feminina, que, à primeira vista, parece ser revolucionária e inovadora, mas em muito se fundamenta nas representações tradicionais do feminino no universo folclórico-religioso russo. Junto a isso, foi impossível ignorar, dada a concepção antitética que, quanto mais explícita era representada a Nova Mulher, mais também aparecia a sua contraposição, a baba.

Em nossa análise, partimos da tese, formulada por Volóchinov (2017, p. 127), de que palavra é um fenômeno ideológico par excellence que reflete e refrata a realidade circundante. Como se sabe, os conceitos desenvolvidos por Mikhail Bakhtin e pelo Círculo influenciaram de modo significativo a escola semiótica russa. Assim, a ideia sobre o papel essencial do contexto na análise semiótica foi desenvolvida posteriormente na semiótica da cultura de lúri Lotman:

Um texto retirado do contexto é uma peça de museu, um armazém de informações constantes. Ele é sempre igual a si mesmo e não é capaz de gerar novos fluxos de informação. O texto no contexto é um mecanismo que funciona, que se transforma e que sempre se recria gerando novas informações (LOTMAN, 2000, p. 676-677).

A consideração do contexto é fundamental, tanto no que diz respeito à tradução dos componentes verbais dos cartazes, quanto na interpretação desses como um todo. Dessa forma, na nossa pesquisa, partimos do pressuposto de que traduzir é também contextualizar. Assim, na interpretação dos cartazes, tornou-se evidente a necessidade de uma combinação entre a abordagem semiótica e histórica do fenômeno.

A complexa inter-relação entre a arte e a realidade, o texto e o contexto, é um dos objetos centrais da semiótica da cultura (LOTMAN, 2001b, p. 12). Por um lado, a realidade, isto é, o contexto, é a condição sine qua non da gênese e da existência de uma obra artística e, por outro, é a fonte inesgotável da renovação da cultura, responsável pela sua dinâmica (LOTMAN, 2001b, p. 129). A realidade irrompe constantemente na cultura, enriquecendo-a e, ao mesmo tempo, transformando-se de acordo com as leis dessa cultura, isto é, por intermédio da memória cultural (PIRES FERREIRA, 1995, p. 117). Concomitantemente, há camadas de informações arremessadas para fora do espaço semiótico (ou seja, esquecidas), mas que certamente voltarão a fazer parte dela em algum momento no futuro, concebidas então como completamente novas (LOTMAN, 2001b, p. 102). 
No que diz respeito à análise dos cartazes em questão, tentaremos mostrar que:

1. Os novos acontecimentos históricos só podem ser interpretados pela cultura ao se encaixarem nos moldes já existentes na memória cultural.

2. Aquilo que uma cultura concebe como "novo" não necessariamente o é de fato, ou, pelo menos, não se trata de algo completamente novo.

\section{A baba e a Nova Mulher}

Na tradução da camada verbal dos cartazes, um dos maiores desafios foi a contextualização e a tradução da palavra baba (бабa, em russo). Por exemplo, no Dicionário de língua russa, encontramos as seguintes significações para esse vocábulo:

1. Uma camponesa casada ou mulher do povo em geral (coloquial).

2. Em geral, sobre uma mulher (às vezes com um tom depreciativo ou irônico) (coloquial). Usado para referir-se à mulher em geral.

3. O mesmo que esposa (na $1^{\mathrm{a}}$ acepção) (coloquial e regional).

4. O mesmo que avó (na $2^{\mathrm{a}}$ acepção) (coloquial e regional); na fala infantil. O mesmo que avó (na $1^{\mathrm{a}}$ acepção).

5. Usado para referir-se a um homem tímido e de caráter fraco (ÓJEGOV; CHVIÉDOVA, 2000, p. 33).

Desse modo, a palavra baba possui em língua russa múltiplas conotações, desde a mulher camponesa até a mulher em geral e/ou mulher idosa. No entanto, para os russos que viviam o momento pós-revolucionário, prevalecia um sentido negativo, de atraso e inferioridade, bem como a imagem visual específica de uma camponesa à moda antiga (BONNELL, 1991, p. 285).

Quanto à tradução, encontramo-nos diante do velho dilema: traduzir a palavra para uma relativamente equivalente ("abrasileirar") ou transliterar e manter o termo original ("manter afastamento") (SCHNAIDERMAN, 2011, p. 28-29)? No primeiro caso, privilegia-se a dimensão linguística, porém, há o risco de aportuguesar demais e perder a dimensão histórico-cultural. Já no segundo, é preciso produzir uma explicação referente ao vocábulo, tentando contextualizá-lo - essa foi a nossa escolha. Um exemplo da impossibilidade da tradução exata do termo baba para a língua portuguesa brasileira, inclusive, é o fato de que seu equivalente masculino, mujique, muito presente nas obras da literatura russa, foi dicionarizado no Brasil como estrangeirismo.

Nos cartazes soviéticos analisados, notamos a prevalência do aspecto negativo da palavra. A baba retratada neles é uma mulher sem estudo, pobre, ignorante, "atrasada" política, cultural e socialmente. Nesse sentido, em 1919, foi criado, junto ao Partido Comunista, o Departamento Feminino (Jenotdel) que, de acordo com a historiadora Elizabeth Wood, objetivava "transformar a baba em uma camarada" (WOOD, 1997, p.4), isto é, em uma Nova Mulher. 
Esse último conceito foi formulado pela revolucionária bolchevique Aleksandra Kollontai, como um fenômeno nascido do "ruído infernal das máquinas da oficina e da sirene das fábricas" (KOLLONTAI, 1978, p. 13). Tal definição abrangia mulheres de diferentes partes do mundo. Apesar de partir de um aspecto econômico - a entrada em massa das mulheres na classe trabalhadora - a Nova Mulher de Kollontai compreende transformações socioculturais profundas com relação à personalidade feminina. A autora chama esse novo tipo de celibatário, caracterizando-o pela liberdade diante das necessidades que antes a prendiam ao lar e pela independência em relação aos indivíduos que antes a submetiam. Era esse tipo de mulher, portanto, o desejado pelo novo governo, para construir a nova sociedade: revolucionária, comunista, trabalhadora, ateia, alfabetizada - em lugar da conservadora, de dona de casa, supersticiosa, analfabeta. No entanto, contraditoriamente, na sociedade soviética, mesmo a Nova Mulher continuava a desempenhar as funções de esposa, mãe e dona de casa (SENNA, 2017, p. 109). São essas oposições semânticas que veremos explicitadas nos cartazes que, tal como a realidade da época, eram permeados por paradoxos e permanências, frente às transgressoras mudanças.

Para além disso, a análise do par nova-antiga mulher nos cartazes propicia pensar outra oposição: mulher urbana e mulher rural. Para a semiótica da cultura, as oposições entre o antigo e o novo, o alheio e o nosso, a cidade e a natureza, são fundamentais na interpretação dos processos que ocorrem no interior de uma cultura (LOTMAN, 2016, p. 243). Nos cartazes, os elementos desses pares ora se entrelaçam, ora se excluem: a representação que primeiramente tomamos por Nova Mulher apenas se confirma caso esteja ali também representada (em imagem ou em público) a mulher urbana. Caso contrário, é outro tipo figurativo - algo entre a baba e a Nova Mulher que se instaura: o ideal de uma camponesa comunista, mas que nunca é de fato vista e colocada como igual.

\section{A representação feminina nos cartazes russos e soviéticos}

No limiar entre os séculos XIX e XX, na Rússia, proliferavam os cartazes comerciais, educacionais e de caridade: fotos de mulheres elegantes e atraentes foram amplamente usadas para promover filmes, revistas, peças de teatro, sociedades, produtos como sabonete, perfume e outros (BONNELL, 1991, p. 269). Aliás, o mesmo processo pode ser observado nos cartazes de propaganda comercial brasileiros da época.

Durante a revolução de 1905 e a Primeira Guerra Mundial, os artistas buscavam representar as ideias de "pátria", "liberdade" e "história", substantivos femininos em língua russa, criando sincretismos alegóricos com imagens femininas (ródina, svobóda, istória), em estilo neoclássico (BONNELL, 1991, p. 274-275). No entanto, a década seguinte foi marcada por profundas transformações não apenas no que diz respeito às reviravoltas político-sociais, como também no que condiz às inovações artísticas que modificaram o gênero de cartaz. 
A revolução de outubro de 1917 foi precedida pela revolução na arte. Nas primeiras três décadas do século XX, houve uma verdadeira explosão em todas as esferas artísticas. Durante esse período de florescimento da arte vanguardista, foram organizadas centenas de exposições, espetáculos, palestras e discussões. Não se tratava de um movimento sólido, mas de um conjunto das tendências artísticas mais variadas que dialogavam entre si: entre elas, arte abstrata, futurismo, primitivismo, suprematismo, construtivismo, a música de Igor Stravínski, a dramaturgia de Konstantin Stanislávski, o cinema de Serguei Eisenstein. Nesse contexto, o poeta-futurista Vladímir Maiakóvski era um dos autores das assim chamadas Janelas do ROST (Ókna ROSTa): cartazes de propaganda em massa produzidos entre 19191921 para a Agência Telegráfica Russa (ROST) e que eram expostos nas janelas e vitrines de lojas. A imagem simples e lacônica geralmente era acompanhada de versos satíricos de fácil percepção e memorização. A contribuição de Maiakóvski abrangia não só a parte poética, como também a gráfica: os seus cartazes traziam marcas de forte influência do abstracionismo e suprematismo.

Apesar da aparente ruptura com a tradução, a arte vanguardista em muito nutria-se da cultura popular. O mesmo pode ser dito a respeito dos cartazes soviéticos. Como nota Bonnell (1991, p. 269), as primeiras representações femininas bolcheviques remetem em grande parte às tradições visuais da Rússia pré-revolucionária. A imagem feminina (por exemplo, as representações da Nossa Senhora nos ícones) era fundamental no universo imagético da Igreja Ortodoxa. Essa relação de forma alguma é ocasional, pois no período pós-revolucionário, como explicita a autora, o Novo Homem e a Nova Mulher, representados nos cartazes de propaganda política, transformaram-se em uma espécie de ícones do novo regime (BONNELL, 1991, p. 269).

Além disso, o cartaz soviético remonta ao gênero lubok, que em muito se aproxima da literatura de cordel brasileira. Tradicional na arte popular russa, o lubok era composto por xilogravuras ou litogravuras com imagens de fácil apercepção, normalmente acompanhadas de uma mensagem explicativa. Os enredos de lubok originavam-se nas narrativas populares e/ou religiosas (ÓJEGOV; SHVÉDOVA, 1999, p. 334).

Entre outras raízes do cartaz soviético e da representação feminina está a iconografia francesa. Assim, contraposta à figura concreta do homem trabalhador e comunista, nos primeiros cartazes pós-revolução a mulher aparecia, de forma ainda mais profunda que antes, como símbolo de conceitos abstratos, como liberdade, igualdade, conhecimento, arte ou história (BONNELL, 1991, p.67). Tal representação trazia a ideia da mulher pura e ideal, que, ao mesmo tempo, distanciava-se da mulher real.

Após o ano de 1917, o cartaz transforma-se de modo definitivo em um dos mais poderosos meios de propaganda política. A explosão cultural (LOTMAN, 2001b) que marcou a primeira década pós-revolução cessa e aos poucos o gênero de cartaz deixa de ser um campo de experimentos e buscas da arte de vanguarda e começa a se solidificar. As tiragens dos cartazes soviéticos impressionam: em alguns casos, elas ultrapassavam 
30 mil cópias (BONNELL, 1991, p. 278). Como resultado desse processo, ocorrem mudanças significativas na representação das mulheres, que deixam de evocar ideias abstratas e se aproximam mais da realidade. No lugar da "liberdade", da "igualdade", da "fraternidade", surgem dois tipos principais: a mulher trabalhadora e a mulher camponesa (BONNELL, 1991, p. 277-287). Ainda assim, a imagem da mulher trabalhadora é bem menos comum do que a do homem trabalhador. Ele era, de fato, o herói principal. Além disso, a mulher camponesa, a baba, era ainda menos vislumbrada que a mulher operária (BONNELL, 1991, p. 284). Além de aparecer em menor número, foi por vezes ironizada e negativizada, como em um famoso cartaz de 1920 do satirista Mikhail Tcheremnykh, baseado nos versos de Vladímir Maiakóvski, História sobre as rosquinhas e a baba que não reconheceu a República (Istória pro búbliki i pro Babu, ne priznaiúchuiu Respúbliki). Nele, uma baba que nega dar uma rosquinha para um soldado do Exército Vermelho acaba sendo devorada junto com o alimento. Tal cartaz foi produzido na guerra civil, quando o Estado obrigava os camponeses a concederem grande parte de sua produção para o exército. Portanto, a obra é uma metonímia da realidade e os camponeses, personificados, não por acaso, na baba, são representados como vilões retrógrados (BONNELL, 1991, p. 284-285).

Em busca de criar uma iconografia própria, mas que dialogasse com o imaginário popular, o novo governo recorria às referências folclóricas e religiosas, isto é, à memória cultural. A figura da mãe-Rússia, símbolo-chave em toda a história do país, que em parte remonta à imagem da Nossa Senhora e às divindades ancestrais que simbolizavam a mãeterra, nos cartazes dos anos 1920-1930 ressurge como mulher trabalhadora ou camponesa.

\section{A baba, a Nova Mulher e a Nossa Senhora da Revolução}

Os dois cartazes que serão objeto de nossa análise a seguir foram selecionados por evidenciarem o processo de construção da Nova Mulher, diante de sua oposição, a baba. Embora as expressões baba e Nova Mulher não apareçam diretamente nos cartazes escolhidos, esses tipos, solidificados pela propaganda soviética, são facilmente reconhecíveis.

O primeiro cartaz (Fig. 1) a nos trazer essas duas representações, Mulher, aprenda a ler e escrever (1923), é de autoria de uma mulher, Elizaveta Krúglikova, algo bastante raro na época. Essa obra inscreve-se em uma série dos cartazes semelhantes, criados com o objetivo de incentivar a alfabetização entre as mulheres. O cartaz confronta, de modo explícito, dois tipos de mulheres: a mulher antiga, representada pela mãe, e a nova mulher, representada pela filha. 


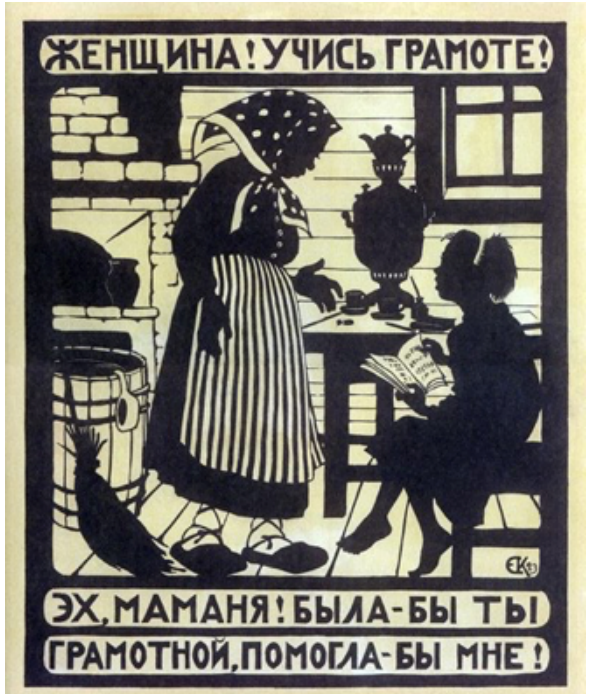

Fig. 1. Mulher, aprenda a ler e escrever! Elizaveta Krúglikova, 1923.

Como afirma Barthes (1982) (representante ilustríssimo da semiótica da cultura, porém da outra vertente, francesa), em seu ensaio sobre a mensagem fotográfica, a estrutura de uma fotografia comunica-se com, no mínimo, mais uma estrutura: o texto. Ambas as estruturas coexistem de modo paralelo e é assim que devem ser analisadas. O mesmo pode ser dito sobre o gênero de cartaz em que se nota o entrelaçamento entre duas linguagens: a visual e a verbal.

Assim, o nível verbal do cartaz consiste em duas partes:

Parte superior: "Mulher! Aprenda a ler e escrever!"

Parte inferior: "Ah, mamãe, se você fosse alfabetizada, poderia me ajudar!"

A parte superior (que o é não por acaso) é dirigida diretamente às mulheres e o seu caráter oficial e imperativo é destacado ainda mais pela brevidade das frases exclamativas. Já a parte inferior representa a voz das próprias mulheres (ou, pelo menos, de uma parte delas) e possui caráter mais íntimo, realçado pela palavra "mamãe".

No que diz respeito ao plano visual, o cartaz inscreve-se perfeitamente no estilo de lubok. A escolha desse gênero não é eventual: trata-se de uma tentativa de aproximar os novos valores do público mais amplo possível, mediante uma iconografia tradicional e folclórica. Ou ainda, de acordo com o pensamento lotmaniamo, trata-se do encaixe do novo nos moldes já existentes na memória cultura. Além disso, como transparece na própria mensagem do cartaz ("Mulher! Aprenda a ler e a escrever!"), o cartaz também é endereçado ao público analfabeto, parte significativa da população russa da época. 
De acordo com Lotman (2002, p. 322), a natureza artística do lubok é específica, pois originalmente as obras criadas nesse gênero eram destinadas ao público dotado de consciência folclórica. O público desse tipo interagia de forma lúdica e ativa com o texto de lubok e, nesse sentido, o seu espaço artístico aproxima-se do teatral, uma vez que o teatro de rua, de feira (balagán), é uma das origens desse gênero (LOTMAN, 2002, p. 324). Inclusive, a presença da moldura, tão comum nas imagens de lubok, assemelha-se ao pano de boca e aos bastidores do espaço teatral.

De fato, no primeiro cartaz, além da moldura, nota-se uma forte influência do universo teatral: a própria encenação gráfica da conversa entre a mãe e a filha, bem como a réplica dessa última no plano verbal ("Ah, mamãe, se você fosse alfabetizada, poderia me ajudar!"). Ou seja, o cartaz não só podia ser percebido e lido pelo público, como também interpretado como uma cena teatral. Outra característica que vincula o cartaz ao universo teatral é a sua natureza zombeteira ou, se utilizarmos o termo de Bakhtin, carnavalesca (LOTMAN, 2002, p. 325). Aqui a carnavalização ocorre mediante a subversão dos papéis tradicionais: a filha sabe mais do que a mãe.

No entanto, para um observador afastado temporal e culturalmente do público-alvo do cartaz, a transformação da mensagem denotativa em conotativa (BARTHES, 1982) ocorre justamente mediante a consideração do contexto histórico em que a obra foi criada. As duas protagonistas, a mãe e a filha, encontram-se em uma oposição. Assim, a moça traz conotação do "novo" que nasceu junto com a revolução: as transformações estéticas, sociais, sexuais vêm a reboque dessa jovem que carrega as novas conquistas e simboliza o novo mundo. O contexto histórico-social não deixa dúvidas quanto aos motivos desse confronto: a mulher mais velha não estudou porque pertence à classe dos camponeses, que praticamente não tinham acesso à educação antes da revolução; já a mais nova, nascida junto com as transformações, teve essa oportunidade. A juventude da moça diz respeito não somente à questão etária, mas também à político-social: ela é jovem, tal como suas ideias são modernas, em consonância com as da revolução.

Tais elementos levam a outra camada de significação: a dicotomia entre mulher camponesa (baba) e mulher urbana. O cenário se passa no campo, na casa da mãe, ambiente que simboliza a Rússia pré-revolucionária. As referências que constroem esse universo são o fogão a lenha, o barril, a vassoura e o tradicional bule de chá (samovar). Porém, todas essas se referem, concomitantemente, não apenas ao campo, mas também, à escravidão doméstica das mulheres. Assim, percebe-se que mesmo sem o cartaz englobar diretamente essa temática, ela está presente. A baba, o exemplo a não ser copiado, representa a imagem tradicional de uma mulher relacionada à cozinha e aos afazeres domésticos. Em oposição, a alfabetização, a educação e a aderência às novas ideias são representadas pela cartilha e pelo lápis, que simbolizam a educação que as camponesas antigas não tiveram. Nas próprias imagens da mulher e da moça há elementos que representam o rural e o urbano e, por consequência, o antigo e o novo: 
as roupas e o calçado feito de palha (lápti) da mulher mais velha, típicos da camponesa tradicional, são colocados frente à roupa moderna e os pés descalços e libertos da filha. A oposição entre a baba (mãe) e a Nova Mulher (filha) é aguçada ainda mais pela paleta dicromática que, aliás, é mais um aspecto que aproxima o cartaz do lubok e da gravura.

A mesma tensão manifesta-se no plano linguístico-textual. Apesar de a mulher mais velha ser caracterizada claramente como uma baba, bem como o público-alvo desse cartaz também ser feminino, a interlocução convoca-a enquanto jénshina (mulher), um termo que não carrega desprezo e nem se relaciona diretamente ao campo. A título de comparação, há outros cartazes da época nos quais o vocativo é baba, e não mulher. Aparentemente, o cartaz sugere alguma possibilidade de transformação - da baba na jénshina, da camponesa na Nova Mulher, transformação essa que é impulsionada pela jovem. No entanto, ainda no nível linguístico-textual destacam-se as exclamações imperativas e o tom de ordem proveniente delas. Mais do que um chamado, há uma crítica à mulher por ela não saber ler. Vê-se, também, pelo conjunto textual (isto é, a oração imperativa e a reclamação da filha) que a transformação, ou seja, a alfabetização, deve ocorrer não para a mulher antiquada crescer pessoalmente, libertar-se dos jugos e ser independente - mas sim, para ensinar a filha. Há, portanto, o reforço do papel histórico da mulher enquanto mãe e educadora dos filhos.

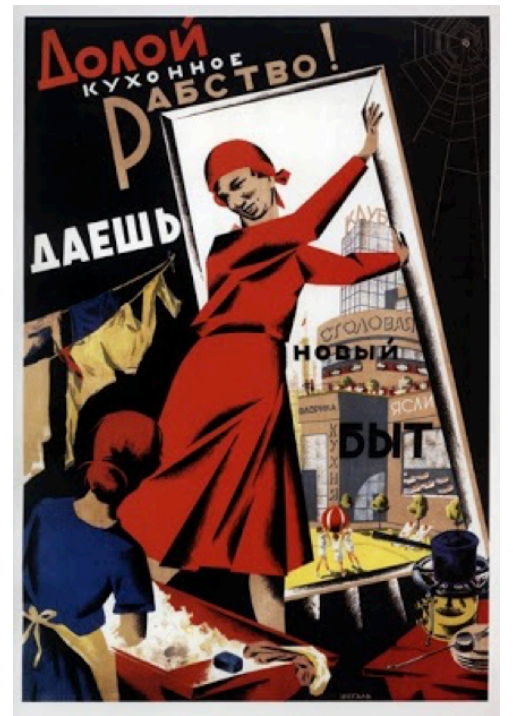

Fig. 2. Abaixo a escravidão na cozinha! Grigóri Shegal, 1931.

O segundo cartaz (Fig. 2) é, provavelmente, um dos mais lembrados e citados quando o assunto é mulher na União Soviética. Produzido em 1931, cerca de uma década após o primeiro, ele representa as mesmas protagonistas: a nova e a velha mulher. No entanto, 
traz diferenças significativas. O cenário mudou: trata-se de um ambiente declaradamente urbano. Além disso, a estética do cartaz é muito mais próxima das conquistas artísticas da vanguarda. À primeira vista, pode parecer que dessa vez o autor não precisou recorrer aos moldes da memória cultural para tornar o conteúdo do cartaz compreensível ao público geral.

No plano central está a figura da trabalhadora comunista: uma verdadeira Nova Mulher. No entanto, aos poucos começamos a reconhecer nela as suas antecessoras. Assim, a posição da trabalhadora evoca a imagem da Liberdade guiando o povo, de Delacroix. Essa associação não é eventual, pois, como lembramos a partir das colocações de Bonnell (1991), a iconografia da Revolução Francesa foi um dos fundamentos para a formação do sistema imagético dos cartazes soviéticos. A cor vermelha das suas roupas é um sinal inegável da sua filiação comunista, além de destacar a virilidade. Entretanto, o vermelho também pode ser interpretado pela ótica da tradição cristã, como alusão ao Cristo e, portanto, à salvação. O lenço na sua cabeça também é um atributo tradicional da cultura russa. Assim, a mãe-camponesa do primeiro cartaz está usando o lenço, ao contrário da filha. De modo geral, tanto o lenço, quanto a face levemente inclinada da primeira mulher (de meio perfil), lembram a representação da Nossa Senhora nos ícones ortodoxos (Fig.3).

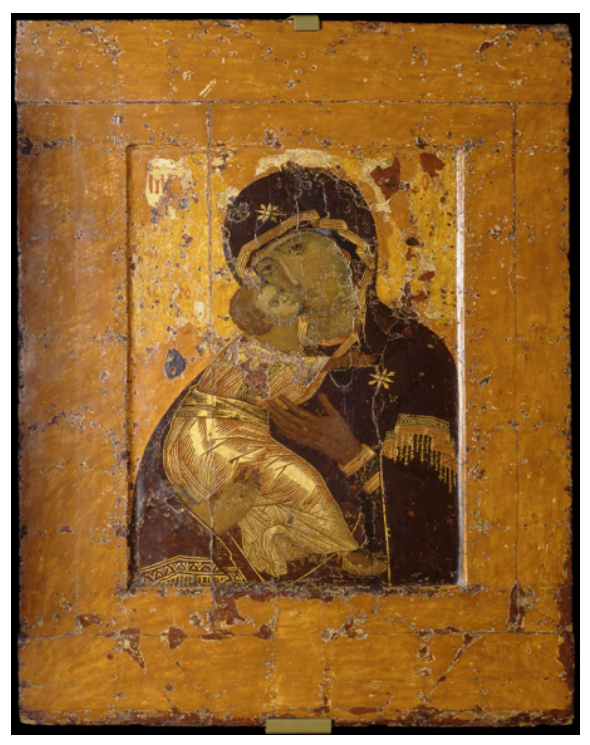

Fig. 3. Nossa Senhora de Vladímir (século XII).

A cor das roupas da segunda mulher, a dona de casa, é azul. Pode parecer que se trata de um mero recurso para distinguir ambas as personagens. No entanto, se voltarmos novamente à simbologia cristã, a combinação do azul e vermelho pode ser relacionada 
à representação do Cristo e da Nossa Senhora. Sob essa ótica, trata-se de uma fusão cromática que une ambas as mulheres. Dessa forma, encontramos novamente relações de hereditariedade entre os ícones e o universo imagético dos cartazes.

No cartaz, "a nova existência" atrás da porta aberta é representada por um prédio que traz as marcas inconfundíveis do construtivismo: abundância do concreto e vidro. A sua face está permeada por todo tipo de letreiros: clube, refeitório, creche, fábrica, cozinha. Realmente, parece ser um futuro muito promissor para as mulheres soviéticas. Do ponto de vista da semiótica da cultura, é um procedimento artístico bastante curioso: uma tentativa de representar o futuro, na verdade imprevisível, como unicamente possível. Assim, a arte demonstra a sua soberania sobre a imprevisibilidade da vida (LOTMAN, 2001b, p. 108).

No entanto, a vida real não foi tão deslumbrante como o futuro do cartaz. As estruturas de lavanderias, refeitórios etc. ainda eram poucas para abarcar toda a população, da forma como havia idealizado o economista soviético Stanislav Strumílin (1877-1974). As filas eram grandes e as unidades ainda concentradas apenas nas áreas urbanas. Como se sabe, as mulheres eram as únicas a trabalharem nas cozinhas e lavanderias comunitárias, o que na prática significava que a sua libertação era apenas parcial. Mesmo seu tempo para o lazer era diminuído, pois ao terminarem um turno de trabalho, por exemplo, numa fábrica, elas ainda teriam que realizar todos os afazeres domésticos na sua casa. Além disso, embora se encontrassem a caminho de uma liberdade parcial das tarefas no lar - e não do lar as mulheres acumulavam o trabalho em relação às pessoas, como filhos, doentes, idosos.

No plano verbal, lemos: "Abaixo a escravidão na cozinha! Dê-nos uma nova existência!". Convergente aos elementos imagéticos, o plano verbal apresenta uma oposição entre a escravidão doméstica e a "nova existência". Aliás, aqui o plano verbal está inserido diretamente no plano imagético, e não separado dele, como no primeiro cartaz. Podemos sugerir que essa confluência de dois planos ocorre devido às transformações do público-alvo: nos anos 1930, a quantidade dos analfabetos de modo geral e das mulheres analfabetas em particular começa a diminuir.

Talvez a encarnação mais representativa das conquistas no que diz respeito à "questão feminina" seja a criação, em 1919, do Departamento das Mulheres do Partido Comunista, que intencionava inserir as mulheres na vida sociopolítica do país. O Departamento foi batizado de Jenotdel, uma abreviação composta de duas palavras: jénski (feminino) e otdiél (departamento) ${ }^{1}$. No entanto, apenas uma década após sua criação, em 5 de janeiro de 1930, a instituição foi dissolvida pelo governo de Stalin. Aqui, faz-se mestra a frase de Chartier (2011, p.17), sobre representar ser colocar presente o que está ausente, já que o cartaz é de 1931, um ano após a dissolução do Jenotdel. Desse modo, é possível supor que o cartaz tenha surgido como uma das tentativas de substituir o departamento

1 Na literatura em língua inglesa ou espanhola e às vezes também em língua portuguesa, a organização é citada como Zhenotdel. Em língua francesa, a palavra costuma ser transliterada como Genotdel. No entanto, segundo a tabela de transliteração sugerida pelo Departamento de Literatura e Cultura Russa da USP (2004), optamos por transliterá-la como Jenotdel. 
- departamento esse que, em discurso, era colocado como não mais necessário. Nesse sentido, o cartaz pode ser interpretado como uma tentativa de suprir a ausência do mesmo: a Nova Mulher representada nele simboliza o próprio Jenotdel.

É curioso observar que ambos os cartazes trazem uma transgressão da perspectiva linear. Assim, no primeiro, a figura da mãe é maior do que a da filha, o que a transforma em uma verdadeira protagonista da obra. Além disso, a sua representação é incomensuravelmente mais detalhada. No segundo cartaz, apesar de estar no primeiro plano, a dona de casa é menor do que a Nova Mulher e ainda se encontra abaixo dela. Trata-se de um fenômeno que o filósofo Floriênski (2012) observou em relação aos ícones ortodoxos e denominou de "perspectiva inversa". Segundo ele, a inversão da perspectiva não resultava da falta de habilidade dos pintores dos ícones, mas era proposital e possuía caráter estético-simbólico. O mesmo pode ser dito sobre os cartazes em questão: no primeiro, a protagonista é a baba, já no segundo, é a Nova Mulher. Além disso, no primeiro, há um abismo histórico-cultural quase irremediável entre a mãe e a filha. Já o segundo apresenta uma possibilidade real de passagem de baba a Nova Mulher. Há diferenças também no plano verbal: se no primeiro caso prevalece tom de ordem, no segundo, ouvimos a voz das próprias mulheres. Assim, apesar de trazerem a mesma oposição entre a baba e a Nova Mulher, os cartazes divergem de modo significativo.

\section{Algumas conclusões}

Em suma, nas primeiras décadas após a Revolução, o Estado soviético de fato teve avanços fascinantes na esfera econômica e educacional: por exemplo, em poucos anos foi declarado o aniquilamento do analfabetismo. No entanto, os retrocessos também eram muitos. Assim, os camponeses não tinham passaporte e não podiam mudar para a cidade -cumpriam, portanto, somente a função de produtores de alimentos para toda a república. Muitos tentavam fugir para as cidades mas, além da dificuldade da ilegalidade, havia também as diferenças culturais, que deixavam visíveis aqueles que não pertenciam aos centros urbanos. Como observamos, no próprio termo baba há um certo desprezo, que refletia, obviamente, o preconceito com as práticas cotidianas. Entendemos, assim, que a maior parte das conquistas favorecia as mulheres dos grandes centros urbanos, mas que, para a baba, não era representada uma saída enquanto Nova Mulher, não apenas porque os sujeitos da época não conseguiam compreendê-la para além do estereótipo, vislumbrando sua transformação em uma representação realmente nova; não apenas porque era necessário haver diálogo e esse deveria partir e ficar apenas no imaginário que já se conhecia; mas, também, porque era perigoso transformar completamente a baba (que representava a Rússia antiga e tradicional) em uma camarada.

Neste estudo, apesar do seu caráter breve e pontual, identificamos algumas contradições entre o discurso oficial e os fatos históricos nas primeiras décadas 
pós-revolução. Como se percebe, a análise histórico-semiótica de apenas dois cartazes já é capaz de evidenciar essas contradições. O cartaz, por ser um gênero de propaganda em massa, representa nitidamente o discurso oficial. Apesar de romper declaradamente com a tradição da Rússia Imperial, a nova ideologia teve o seu corpus simbológico embasado no imaginário religioso e folclórico-mitológico. Do mesmo modo, no plano histórico, apesar das declarações sobre o novo papel da mulher soviética e os seus direitos, houve muitos regressos e incongruências. Além disso, a distinção que identificamos nos cartazes entre a baba e a Nova Mulher, estudada por meio das oposições semânticas entre o antigo e o novo, a tradição e a inovação, a cidade e o campo, revela que a baba desempenhava neles o papel do "outro". Por um lado, ela propiciava a definição das características desejáveis da Nova Mulher soviética - que nasce a partir do que ela não é e à custa da inferiorização de outros tipos femininos; por outro, a baba é a origem, a mãe da Nova Mulher.

Ekaterina Vólkova Américo é professora de Literatura e Língua russa da Universidade Federal Fluminense, tradutora e pesquisadora das obras de lúri Lotman, Mikhail Bakhtin e seu Círculo, Roman Jakobson e Piotr Bogatyriov, entre outros. É doutora pelo Programa de Pós-graduação em Literatura e Cultura Russa pela Universidade de São Paulo e mestre pela Universidade Russa das Humanidades (Rússia, Moscou).

katia-v@ya.ru

Thaiz Carvalho Senna é doutoranda em História Contemporânea pela Universidade Federal Fluminense (UFF). Participa do projeto de tradução de materiais em Língua Russa, com foco em documentação soviética pelo Laboratório de Tradução da UFF (LABESTRAD).

thaizsenna@gmail.com

\section{Referências}

BARTHES, R. A mensagem fotográfica. In: LIMA, Luiz Costa (Org.). Teoria da cultura de massa. Rio de Janeiro: Paz e Terra, 1982, p. 299-316.

BONNELL, V. E. The Representation of Women in Early Soviet Political Art. Russian Review, v. 50, n. 3. p. 267-288, Jul., 1991. Disponível em: http://links.jstor.org/sici?sici=0036-0341\%28199107\%2950\%3A3 \%3C267\%3ATROWIE\%3E2.0.CO\%3B2-3 Acesso em: 07/04/2017.

CHARTIER, R. Defesa e ilustração da noção de representação. Fronteiras, Dourados, v. 13, n. 24, p. 15-29, jul./dez. 2011. Disponível em: http://www.ufrgs.br/gthistoriaculturalrs/nocaoderepresentacao. pdf Acesso em: 05/04/2017. 
FLORIÊNSKI, P. A perspectiva inversa. São Paulo: Editora 34, 2012.

KOLLONTAI, A. A nova mulher e a moral sexual. Rio de Janeiro: Global, 1978[1918].

LOTMAN, I. Semiosfera. São Petersburgo: Iskússtvo-SPB, 2001.

O conceito de fronteira. In: O espaço literário. BORGES FILHO, O. (org.) Textos teóricos. Uberaba: Ribeirão Gráfica Editora, 2016, p. 243-258.

ÓJEGOV, S. I.; CHVIÉDOVA, N. lu. Tolkóvyi slovar rússkogo iazyká (Dicionário de língua russa). Moscou: Azbukóvnik, 1999.

PIRES FERREIRA, J. Cultura é memória. In: Revista USP, n. 24, 1995, p. 114-120.

SCHNAIDERMAN, B. Tradução, ato desmedido. São Paulo: Perspectiva, 2011.

Tabela de transliteração do Russo para o Português. Caderno de Literatura e Cultura Russa. No 1, 2004, p. 393.

SENNA, T. C. A questão da representação feminina nos cartazes soviéticos - Algumas questões. História e Cultura. MUNDIM, L. F. C.; PINTO, T. S. (orgs.), v. 6, n. 1, p. 103-125, mar. 2017.

VOLÓCHINOV, V. Marxismo e Filosofia da Linguagem. São Paulo: Editora 34, 2017.

Artigo recebido em 20 de abril e aprovado em 13 de agosto de 2017. 